\title{
Co-cultivation, Co-culture, Mixed Culture, and Microbial Consortium of Fungi: An Understudied Strategy for Biomass Conversion
}

\author{
Matheus Sanitá Lima ${ }^{1 * \dagger}$ and Rosymar Coutinho de Lucas ${ }^{2,3 * \dagger}$ \\ ${ }^{1}$ Department of Biology, University of Western Ontario, London, ON, Canada, ${ }^{2}$ Department of Biology, Faculty of Philosophy, \\ Sciences and Letters of Ribeirão Preto, University of São Paulo, Ribeirão Preto, Brazil, ${ }^{3}$ Department of Parasitology, \\ Microbiology and Immunology, Institute of Biological Sciences, Federal University of Juiz de Fora, Juiz de Fora, Brazil
}

Keywords: co-cultivation, co-culture, mixed culture, microbial consortium, microbial blend, biomass conversion, biorefinery, fungi

OPEN ACCESS

Edited by:

Luciana Fernandes de Brito, Norwegian University of Science and

Technology, Norway

Reviewed by:

Wensheng Qin

Lakehead University, Canada

*Correspondence:

Matheus Sanitá Lima

msanital@uwo.ca

Rosymar Coutinho de Lucas

rosymar_lucas@hotmail.com

†These authors have contributed equally to this work and share first authorship

Specialty section:

This article was submitted to

Microbiotechnology,

a section of the journal

Frontiers in Microbiology

Received: 16 December 2021 Accepted: 29 December 2021

Published: 20 January 2022

Citation:

Sanitá Lima M and Coutinho de Lucas $R$ (2022) Co-cultivation,

Co-culture, Mixed Culture, and Microbial Consortium of Fungi: An Understudied Strategy for Biomass

Conversion.

Front. Microbiol. 12:837685 doi: $10.3389 /$ fmicb.2021.837685

\section{INTRODUCTION}

Sixty years have passed since Rachel Carson published her seminal book "Silent Spring" (Carson, 1962). Her work catapulted the ecological movement and shaped modern environmentalism (Kroll, 2001). However, fast-forward to present day and we seem not to have paid enough attention to the environment. Guidelines for a sustainable future have been repeatedly proposed and the planetary boundaries for our safe existence have been established (Rockström et al., 2009). Yet, more than $80 \%$ of the current global energy consumption still relies on unsustainable fossil fuels ${ }^{1}$ (Ritchie and Roser, 2020) and the COP26 negotiations have not delivered (Sheather, 2021). To make things worse, the demand for oil and gas is expected to peak in the next two decades. ${ }^{2}$ The prevailing linear economy based on the take-make-dispose system is unsustainable (Sariatli, 2017) and climate change already affects biological systems around the globe (Freitas et al., 2021). There will not be a "one-stop shop" type of solution, but we need to transition to a circular economy and biorefineries are a great place to start (Ubando et al., 2020). Among several models, the lignocellulosic biorefinery concept is prominent (Silva et al., 2018) and this is where fungi occupy a special place.

\section{FUNGI-THE WORKHORSE FOR THE PRODUCTION OF LIGNOCELLULOLYTIC ENZYMES}

The importance of fungi for several industries is undeniable. These microorganisms produce enzymes that are used in a wide range of processes, from bread-making to paper manufacturing (Polizeli et al., 2005). But it is as producers of lignocellulolytic enzymes that fungi could be called a true workhorse. To put in (historical) perspective, the fungus Trichoderma reesei was first identified as a great cellulase producer over 75 years ago (Bischof et al., 2016). Since then, lignocellulolytic fungi have been studied to an unparalleled extent. Their enzymes have been characterized (Benassi et al., 2012), immobilized (da Silva et al., 2014), engineered (Furtado et al., 2015) and expressed in heterologous systems (Ribeiro et al., 2014). Several fungi have been screened for their lignocellulolytic capabilities (Benassi et al., 2014), and entire fungal genomes

\footnotetext{
${ }^{1}$ https://www.bp.com/en/global/corporate/energy-economics/statistical-review-of-world-energy.html

${ }^{2}$ https://www.mckinsey.com/\$sim\$/media/McKinsey/Industries/Oil\%20and\%20Gas/Our\%20Insights/Global\%20Energy

\%20Perspective\%202021/Global-Energy-Perspective-2021-final.pdf
} 
have been investigated in the search for holocellulose degrading pathways (Segato et al., 2014). Enzymatic cocktails derived from multiple fungi have been formulated as well (Pinheiro et al., 2021). However, the co-cultivation of fungi has lagged among the plethora of strategies for the production of lignocellulolytic enzymes. Broadly speaking, co-cultivation of microorganisms is the cultivation of two or more microbial strains combined within the same laboratory flask, Petri dish or fermentation tank. A co-cultivation can be referred also as a co-culture, mixed culture, mixed fermentation (more commonly used in submerged fermentation studies), microbial blend and microbial consortium. We use these terms interchangeably throughout the text, but in our discussion, we point to the potential advantages of having a standardized nomenclature. We have applied fungal co-cultures in biomass conversion studies (Sanitá Lima et al., 2016), and we now argue that there is a need (and opportunity) to take this strategy to a new level. Below, we identify some aspects that are missing in co-cultivation studies and present possible strategies for the community to move forward in this realm. These ideas stem from studies in fungal physiology, community ecology and synthetic biology. In fact, co-cultivation of microorganisms has long been applied in the investigation of natural products (Bertrand et al., 2014) and the development of synthetic biology techniques (Goers et al., 2014). Therefore, we believe greater cross-disciplinary discussions would enrich and spur strategies to produce fungal lignocellulolytic enzymes.

\section{THE METABOLIC BLACK-BOX OF FUNGAL CO-CULTURES}

Fungi are extensively used in biotechnology, precisely because of their innate capacity to produce several proteins. As part of the fungal primary metabolism, lignocellulolytic enzymes are readily secreted according to growth conditions (de Lucas et al., 2021). But fungi have an intricate secondary metabolism and secrete numerous compounds into the culture medium (Frisvad, 2015). Although primary and secondary metabolites have been studied as separate entities, microorganisms know how to blurry our artificial classifications (Kistler and Broz, 2015). From day one, fungi produce compounds of diverse chemical nature that control spore germination, mycelial growth, clonal reproduction and defense (Leeder et al., 2011). Many of these molecules are density-dependent and act on quorum sensing (Albuquerque and Casadevall, 2012). Several other metabolites trigger the activation of silent gene clusters through elusive mechanisms of interspecies crosstalk (Marmann et al., 2014). This is how co-cultures quickly become a metabolic black-box. This is also where co-cultivation studies for the production of lignocellulolytic enzymes lack insight. Bacterial co-cultures, mostly referred as microbial/bacterial consortia, have been investigated to much greater detail and possess wider applications. In fact, bacterial consortia are fabricated for specific biotechnological goals (Vortmann et al., 2021). Synthetic microbial consortia borrow ecological concepts, such as amensalism and commensalism, to engineer high performance multi-species systems (Sgobba and Wendisch, 2020). Although co-cultivating fungi to produce better enzymatic cocktails is not a brand-new idea (Zoglowek et al., 2016), the studies within this domain fare poorly compared to their bacterial counterparts in terms of insight. Most experiments grow two to three strains under the same conditions used for the cultivation of one single strain (Sperandio and Filho, 2021). The effects of inoculum volume ratio (Rabello et al., 2014) and time (Kolasa et al., 2014) can be investigated, but this is not common place. So, secondary metabolites that can exert antagonistic effects are not taken into consideration and the co-cultivation performance (i.e., the final hydrolysis yield) is a result of trial-and-error. The co-cultures mostly have only fungi and use at least one strain that is known to be a good producer of biomass degrading enzymes (Wang et al., 2015). Several carbon and nitrogen sources are generally tested (Sperandio and Filho, 2019), but the effects of the fermentation style on the growing fungi are hard to tease apart in current setups.

Co-cultures have clear advantages over their axenic counterparts (Sperandio and Filho, 2019). Growing several strains altogether will reduce production costs, as inputs and human labor are better used. With the right strains, co-cultures can be more resistant to contamination and produce more powerful (i.e., synergistic) enzymatic cocktails (Gutiérrez-Correa and Villena, 2012). The emphasis here is on "right strains" and "synergistic" cocktails. Co-cultures tend to exhibit higher yields of biomass saccharification, but claims about multi-enzyme synergism can be loosely made. In fact, at the end of these experiments very little is known other than the final amount of reducing sugars released. Are the co-cultured (co-expressed?) enzymes acting synergistically or additively? What about the co-cultivation attempts that did not present higher yields of biomass hydrolysis? Have the co-cultured fungi inhibited each other via secondary metabolites or have the fungi run out of carbon source before producing all their enzymes? These are some questions that are commonly not present in most cocultivation studies aiming to produce lignocellulolytic enzymes. The consequent lack of insight brought about by experimental design blind spots not only prevents the community from finding promising co-cultures, but also hinders the possibility of these systems being scaled-up. If experiments do not account for the inter-species metabolic talk happening inside an Erlenmeyer, how could these strategies be scaled up to industry applications?

We understand that these studies are focused on the production of cellulases, xylanases, and lignin-modifying enzymes. It is unfeasible to dissect every single co-culture using fully fledged metabolomics, proteomics, transcriptomics and epigenomics techniques. This is why we believe standardized group effort is the way to move forward. Co-cultivation systems represent a valuable (and untapped) source of multi-enzyme cocktails. We need cooperation across disciplines to make this strategy a successful approach.

\section{DISCUSSION}

What is in a name can create momentum around scientific findings and help spread concepts (Smith and James, 2013). 
In an attempt to strengthen the studies of lignocellulolytic co-cultures, our first suggestion is for researchers to adopt a common language. Currently, growing concomitantly several microorganisms for a specific purpose can be called a co-culture, mixed cultured, co-cultivation, mixed fermentation, microbial (e.g., fungal) consortium, microbial cocktail, and microbial blend. This list is not comprehensive and name variants exist depending on the applications of the study. Although certain name choices hold intrinsic value according to different fields, having a cross-disciplinary nomenclature can help with scientific dissemination and galvanize collaborations. In fact, we are not the first ones to highlight the need for standardized names. Del Frari and Ferreira (2021) have proposed the term "skopobiota" to move forward, for instance.

Our other suggestion is the creation of a database of cocultures. Databases have been fundamental to data-rich research endeavors in molecular evolution (Smith and Sanitá Lima, 2017) and microbial community ecology (Sanitá Lima et al., 2019). However, databases must be standardized and possibly curated for them to hold meaning and value in springing future research (Sanitá Lima and Smith, 2017). As researchers start to adopt a common nomenclature, each co-cultivation assay could be stored in this "database of co-cultures." Experimental variables, such as cultivation conditions, and number and name of strains, could be standard entries that would be easily retrieved for future reference and comparative analyses. Each combination of fungi, pairwise or not, could be classified according to their ecological interactions-whether there was commensalism, mutualism, antagonism, etc. Data pertaining to metabolic, proteomic, transcriptomic and epigenomic analyses could be added. This would serve as a roadmap to indicate knowledge gaps and possible points of reference-the species $\mathrm{X}$ with commensal $\mathrm{Y}$ produced metabolite $\mathrm{Z}$ after $\mathrm{W}$ days. As data are gathered, the database could give rise to a mix-and-match system through which future co-cultures would be more easily designed and enzymatic cocktails optimized. This approach resembles the prolific tinkering of other systems, such as the OSMAC approach

\section{REFERENCES}

Albuquerque, P., and Casadevall, A. (2012). Quorum sensing in fungi - a review. Med. Mycol. 50, 337-345. doi: 10.3109/13693786.2011.652201

Banerjee, G., Car, S., Scott-Craig, J. S., Borrusch, M. S., Bongers, M., and Walton, J. D. (2010). Synthetic multi-component enzyme mixtures for deconstruction of lignocellulosic biomass. Bioresour. Technol. 101, 9097-9105. doi: 10.1016/j.biortech.2010.07.028

Benassi, V. M., da Silva, T. M., Pessela, B. C., Guisan, J. M., Mateo, C., Lima, M. S., et al. (2012). Immobilization and biochemical properties of $\beta$-xylosidase activated by glucose/xylose from Aspergillus niger USP67 with transxylozylation activity. J. Mol. Catal. B Enzym. 89, 93-101. doi: 10.1016/j.molcatb.2012.12.010

Benassi, V. M., de Lucas, R. C., Jorge, J. A., and Polizeli, M. L. T. M. (2014). Screening of thermotolerant and thermophilic fungi aiming $\beta$ xylosidase and arabinanase production. Braz. J. Microbiol. 4, 1459-1467. doi: $10.1590 / \mathrm{S} 1517-83822014000400042$

Bertrand, S., Bohni, N., Schnee, S., Schumpp, O., Gindro, K., and Wolfender, J.-L. (2014). Metabolite induction via microorganism co-culture: a potential way to
(Bode et al., 2002) and GENPLAT platform (Banerjee et al., 2010). The possibilities are endless, just like the potentialities of the co-cultivation of lignocellulolytic fungi.

The current costs for the production of lignocellulosic biofuels are still mostly prohibitive (Rosales-Calderon and Arantes, 2019). Great part of these costs derives from the biomass pretreatment and production of enzymes for biomass saccharification (de Oliveira Gorgulho Silva and Filho, 2017). Co-cultivation of lignocellulolytic fungi can produce cheaper enzymes and make biomass conversation technologies more feasible. Studying fungal enzymes has spawned profitable industries and decadeslong research programs. These enzymes will not save the world, but can certainly contribute to a less wasteful one. The transition from a linear present to a circular future is a true maze, and we need to start from somewhere. Otherwise, we risk not only having a silent spring, but a silent planet.

\section{AUTHOR CONTRIBUTIONS}

MS and RC conceptualized the idea, investigated pertinent literature, discussed concepts, and wrote the manuscript. All authors approved the final version.

\section{FUNDING}

Previous research that spawned this work has been funded by the National Council for Scientific and Technological Development (CNPq) and Fundação de Amparo à Pesquisa do Estado de São Paulo (FAPESP).

\section{ACKNOWLEDGMENTS}

We thank our lab mates for the fruitful discussions that originated this opinion. We are thankful to professor David Roy Smith for his enriching suggestions. We also thank the reviewers for their insightful comments and consequent improvements of the manuscript. enhance chemical diversity for drug discovery. Biotechnol. Adv. 32, 1180-1204. doi: 10.1016/j.biotechadv.2014.03.001

Bischof, R. H., Ramoni, J., and Seiboth, B. (2016). Cellulases and beyond: the first 70 years of the enzyme producer Trichoderma reesei. Microb. Cell Fact. 15:106. doi: 10.1186/s12934-016-0507-6

Bode, H. B., Bethe, B., Höfs, R., and Zeeck, A. (2002). Big effects from small changes: possible ways to explore nature's chemical diversity. Chembiochem 3, 619-627. doi: 10.1002/1439-7633(20020703)3:7<619::AID-CBIC619>3.0.CO;2-9

Carson, R. (1962). Silent Spring. Boston: Houghton Mifflin Harcourt.

da Silva, T. M., Pessela, B. C., da Silva, J. C. R., Lima, M. S., Jorge, J. A., and Polizeli, M. L. T. M. (2014). Immobilization and high stability of an extracellular $\beta$ glucosidase from Aspergillus japonicus by ionic interactions. J. Mol. Catal. B Enzym. 104, 95-100. doi: 10.1016/j.molcatb.2014.02.018

de Lucas, R. C., de Oliveira, T. B., Sanitá Lima, M., Pasin, T. M., Scarcella, A. S. A., Ribeiro, L. F. C., et al. (2021). The profile secretion of Aspergillus clavatus: different pre-treatments of sugarcane bagasse distinctly induces holocellulases for the lignocellulosic biomass conversion into sugar. Renew. Energy 165, 748-757. doi: 10.1016/j.renene.2020.11.072 
de Oliveira Gorgulho Silva, C., and Filho, E. X. F. (2017). A review of holocellulase production using pretreated lignocellulosic substrates. Bioenerg. Res. 10, 592-602. doi: 10.1007/s12155-017-9815-x

Del Frari, G., and Ferreira, R. B. (2021). Microbial blends: terminology overview and introduction of the neologism "Skopobiota". Front. Microbiol. 12:659592. doi: $10.3389 /$ fmicb.2021.659592

Freitas, E. N., d., Salgado, J. C. S., Alnoch, R. C., Contato, A. G., Habermann, E., et al. (2021). Challenges of biomass utilization for bioenergy in a climate change scenario. Biology 10:1277. doi: 10.3390/biology10121277

Frisvad, J. C. (2015). Taxonomy, chemodiversity, and chemoconsistency of Aspergillus, Penicillium, and Talaromyces species. Front. Microbiol. 5:773. doi: $10.3389 /$ fmicb.2014.00773

Furtado, G. P., Santos, C. R., Cordeiro, R. L., Ribeiro, L. F., de Moraes, L. A. B., Damásio, A. R. L., et al. (2015). Enhanced xyloglucan-specific endo- $\beta-1,4-$ glucanase efficiency in an engineered CBM44-XegA chimera. Appl. Microbiol. Biotechnol. 99, 5095-5107. doi: 10.1007/s00253-014-6324-0

Goers, L., Freemont, P., and Polizzi, K. M. (2014). Co-culture systems and technologies: taking synthetic biology to the next level. J. R. Soc. Interface 11:20140065. doi: 10.1098/rsif.2014.0065

Gutiérrez-Correa, M., and Villena, G. K. (2012). Batch and repeated batch cellulase production by mixed cultures of Trichoderma reesei and Aspergillus niger or Aspergillus phoenicis. J. Microbiol. Biotech. Res. 2, 929-935.

Kistler, H. C., and Broz, K. (2015). Cellular compartmentalization of secondary metabolism. Front. Microbiol. 6:68. doi: 10.3389/fmicb.2015.00068

Kolasa, M., Ahring, B. K., Lübeck, P. S., and Lübeck, M. (2014). Cocultivation of Trichoderma reesei RutC30 with three black Aspergillus strains facilitates efficient hydrolysis of pretreated wheat straw and shows promises for on-site enzyme production. Bioresour. Technol. 169, 143-148. doi: 10.1016/j.biortech.2014.06.082

Kroll, G. (2001). The 'Silent Springs' of Rachel Carson: mass media and the origins of modern environmentalism. Public Underst. Sci. 10, 403-420. doi: 10.1088/0963-6625/10/4/304

Leeder, A. C., Palma-Guerrero, J., and Glass, N. (2011). The social network: deciphering fungal language. Nat. Rev. Microbiol. 9, 440-451. doi: 10.1038/nrmicro2580

Marmann, A., Aly, A. H., Lin, W., Wang, B., and Proksch, P. (2014). Cocultivation - a powerful emerging tool for enhancing the chemical diversity of microoganisms. Mar. Drugs 12, 1043-1065. doi: 10.3390/md12021043

Pinheiro, V. E., Horváth, I. S., Lundin, and, M., and Polizeli, M. L. T. M. (2021). Screening and cocktail optimization using experimental mixture design: enzymatic saccharification as a biological pretreatment strategy. Biofuel Bioprod. Biorefin. 15, 1447-1460. doi: 10.1002/bbb.2251

Polizeli, M. L. T. M., Rizzatti, A. C. S., Monti, R., Terenzi, H. F., Jorge, J. A., and Amorim, D. S. (2005). Xylanases from fungi: properties and industrial applications. Appl. Microbiol. Biotechnol. 67, 577-591. doi: $10.1007 / \mathrm{s} 00253-005-1904-7$

Rabello, G. C., Pirota, R. D. P. B., Barros, G. O. F., and Farinas, C. S. (2014). Simultaneous biosynthesis of biomass-degrading enzymes using co-cultivation of Aspergillus niger and Trichoderma reesei. Biocatal. Biotransform. 32, 236-243. doi: $10.3109 / 10242422.2014 .934362$

Ribeiro, L. F., de Lucas, R. C., Vitcosque, G. L., Ribeiro, L. F., Ward, R. J., Rubio, M. V., et al. (2014). A novel thermostable xylanase GH10 from Malbranchea pulchella expressed in Aspergillus nidulans with potential applications in biotechnology. Biotechnol. Biofuels 7:115. doi: 10.1186/1754-6834-7-115

Ritchie, H., and Roser, M. (2020). Energy. Our World in Data. Available online at: https://ourworldindata.org/energy (accessed December 1, 2021).

Rockström, J., Steffen, W., Noone, K., Persson, Å., Chapin, F. S. I. I. I., Lambin, E., et al. (2009). Planetary boundaries: exploring the safe operating space for humanity. Ecol. Soc. 14:32. doi: 10.5751/ES-03180-140232

Rosales-Calderon, O., and Arantes, V. (2019). A review on commercial-scale highvalue products that can be produced alongside cellulosic ethanol. Biotechnol. Biofuels 12:240. doi: 10.1186/s13068-019-1529-1

Sanitá Lima, M., Damásio, A. R. L., Crnkovic, P. M., Pinto, M. R., da Silva, A. M., da Silva, J. C. R., et al. (2016). Co-cultivation of Aspergillus nidulans recombinant strains produces an enzymatic cocktail as alternative to alkaline sugarcane bagasse pretreatment. Front. Microbiol. 7:583. doi: 10.3389/fmicb.2016.00583
Sanitá Lima, M., de Lucas, R. C., Lima, N., Polizeli, M. L. T. M., and Santos, C. (2019). Fungal community ecology using MALDI-TOF MS demands curated mass spectral databases. Front. Microbiol. 10:315. doi: $10.3389 /$ fmicb.2019.00315

Sanitá Lima, M., and Smith, D. R. (2017). Don't just dump your data and run. EMBO Rep. 18, 2087-2089. doi: 10.15252/embr.201745118

Sariatli, F. (2017). Linear economy versus circular economy: a comparative and analyzer study for optimization of economy for sustainability. Visegrad J. Bioecon. Sustain. Dev. 6, 31-34. doi: 10.1515/vjbsd-2017-0005

Segato, F., Damásio, A. R. L., de Lucas, R. C., Squina, F. M., and Prade, R. A. (2014). Genomics review of holocellulose deconstruction by aspergilli. Microbiol. Mol. Biol. Rev. 78, 588-613. doi: 10.1128/MMBR.00019-14

Sgobba, E., and Wendisch, V. F. (2020). Synthetic microbial consortia for small molecule production. Curr. Opin. Biotechnol. 62, 72-79. doi: 10.1016/j.copbio.2019.09.011

Sheather, J. (2021). The conflicts that killed COP26. BMJ 375:n2798 doi: $10.1136 /$ bmj.n2798

Silva, C. O. G., Vaz, R. P., and Filho, E. X. F. (2018). Bringing plant cell walldegrading enzymes into the lignocellulosic biorefinery concept. Biofuel Bioprod. Biorefin. 12, 277-289. doi: 10.1002/bbb.1832

Smith, D. R., and James, E. R. (2013). What's in a name? A lot if you're a little-known microbe. BioScience 63, 791-792. doi: 10.1525/bio.2013.63.10.5

Smith, D. R., and Sanitá Lima, M. (2017). Unraveling chloroplast transcriptomes with ChloroSeq, an organelle RNA-Seq bioinformatics pipeline. Brief. Bioinformatics 18, 1012-1016. doi: 10.1093/bib/bbw088

Sperandio, G. B., and Filho, E. X. F. (2019). Fungal co-cultures in the lignocellulosic biorefinery context: a review. Int. Biodeterior. Biodegradation 142, 109-123. doi: 10.1016/j.ibiod.2019.05.014

Sperandio, G. B., and Filho, E. X. F. (2021). An overview of Trichoderma reesei co-cultures for the production of lignocellulolytic enzymes. Appl. Microbiol. Biotechnol. 105, 3019-3025. doi: 10.1007/s00253-021-11261-7

Ubando, A. T., Felix, C. B., and Chen, W.-H. (2020). Biorefineries in circular bioeconomy: a comprehensive review. Bioresour. Technol. 299:122585. doi: 10.1016/j.biortech.2019.12 2585

Vortmann, M., Stumpf, A. K., Sgobba, E., Dirks-Hofmeister, M. E., Krehenbrink, M., Wendisch, V. F., et al. (2021). A bottom-up approach towards a bacterial consortium for the biotechnological conversion of chitin to L-lysine. Appl. Microbiol. Biotechnol. 105, 1547-1561. doi: 10.1007/s00253-021-11112-5

Wang, H., Peng, L., Ding, Z., Wu, J., and Shi, G. (2015). Stimulated laccase production of Pleurotus ferulae JM301 fungus by Rhodotorula mucilaginosa yeast in co-culture. Process Biochem. 50, 901-905. doi: 10.1016/j.procbio.2015.0 3.004

Zoglowek, M., Hansen, G. H., Lübeck, P. S., and Lübeck, M. (2016). "Fungal consortia for conversion of lignocellulose into bioproducts," in Fungal Biotechnology for Biofuel Production, ed R. N. Silva (Sharjah: Bentham Science Publishers), 329-365.

Conflict of Interest: The authors declare that the research was conducted in the absence of any commercial or financial relationships that could be construed as a potential conflict of interest.

Publisher's Note: All claims expressed in this article are solely those of the authors and do not necessarily represent those of their affiliated organizations, or those of the publisher, the editors and the reviewers. Any product that may be evaluated in this article, or claim that may be made by its manufacturer, is not guaranteed or endorsed by the publisher.

Copyright (c) 2022 Sanitá Lima and Coutinho de Lucas. This is an open-access article distributed under the terms of the Creative Commons Attribution License (CC $B Y)$. The use, distribution or reproduction in other forums is permitted, provided the original author(s) and the copyright owner(s) are credited and that the original publication in this journal is cited, in accordance with accepted academic practice. No use, distribution or reproduction is permitted which does not comply with these terms. 